\title{
Hydrogen isotope exchange mechanism in tungsten studied by ERDA
}

\section{Vuoriheimo, Tomi}

2020-01-01

Vuoriheimo , T , Jalkanen , P , Liski , A, Mizohata , K, Ahlgren , T , Heinola , K \& Räisänen , J 2020 , ' Hydrogen isotope exchange mechanism in tungsten studied by ERDA ', Physica Scripta , vol. T171, no. 1 , 014056 . https://doi.org/10.1088/1402-4896/ab57ad

http://hdl.handle.net/10138/328026

https://doi.org/10.1088/1402-4896/ab57ad

unspecified

acceptedVersion

Downloaded from Helda, University of Helsinki institutional repository.

This is an electronic reprint of the original article.

This reprint may differ from the original in pagination and typographic detail.

Please cite the original version. 


\title{
Hydrogen isotope exchange mechanism in tungsten studied by ERDA
}

\author{
Tomi Vuoriheimo ${ }^{1}$, Pasi Jalkanen ${ }^{1}$, Anna Liski ${ }^{1}$, Kenichiro Mizohata ${ }^{1}$, Tommy \\ Ahlgren $^{1}$, Kalle Heinola ${ }^{2,1}$ and Jyrki Räisänen ${ }^{1}$ \\ ${ }^{1}$ Department of Physics, University of Helsinki, Helsinki, Finland \\ ${ }^{2}$ International Atomic Energy Agency IAEA, Vienna, Austria \\ E-mail: tomi.vuoriheimo@helsinki.fi
}

Received xxxxxx

Accepted for publication $\mathrm{xxxxxx}$

Published xxxxxx

\begin{abstract}
Future fusion reactors use a D-T plasma mixture as fuel. A fraction of hydrogen species can escape the plasma confinement and hit the first wall. Hydrogen isotope exchange, a process in which trapped $\mathrm{T}$ atoms are replaced with lighter hydrogen isotopes $\mathrm{D}$ or $\mathrm{H}$, is a potential method to minimize radioactive $\mathrm{T}$ retention in the wall materials. The present work extends our systematic research on isotope exchange by reversing the process, i.e., by implanting $\mathrm{H}$ ions into tungsten followed by subsequent annealing at different constant temperatures in $\mathrm{D}_{2}$ atmosphere. Elastic Recoil Detection Analysis was used to determine the H and D concentrations. The results show that the isotope exchange process takes place regardless of the mass of the active hydrogen isotope. This indicates that the isotope exchange is a statistical phenomenon in which the abundance of the neighboring hydrogen near the trapped hydrogen isotope defines the efficiency of the process.
\end{abstract}

Keywords: isotope exchange, retention, fusion, tungsten, ion beam analysis, annealing

\section{Introduction}

In future fusion reactors a fuel mixture of deuterium (D) and tritium (T) plasma is planned to be used. $\mathrm{T}$ can be trapped to the plasma-facing components (PFCs) of the reactor chamber. As $\mathrm{T}$ is radioactive its retention in fusion devices must be limited for operational and safety reasons. The problem of how to reduce unwanted $\mathrm{T}$ retention in the PFCs is being extensively studied. One way is to choose a PFC material which does not retain T excessively. Currently tungsten $(\mathrm{W})$ is the material considered to be used but other materials are under research as well. Another way to minimize the accumulated $\mathrm{T}$ retention in the PFCs is to find ways on how to remove it efficiently in between operational periods. A widely studied removal method is based on baking of the PFCs at elevated temperatures. An alternative approach is the utilization of the isotope exchange process.
In a typical isotope exchange process an isotope trapped in the bulk of the material is being replaced with a lighter isotope of the same species. In case of PFCs it can be used to remove radioactive $\mathrm{T}$ by replacing it with protium $(\mathrm{H})$ or $\mathrm{D}$. Isotope exchange can be used as a supplementary method to decrease $\mathrm{T}$ inventory more efficiently than just by annealing in vacuum. To achieve efficient isotope exchange an excess amount of the added replacing isotope must be as solute in the system. Once an atom of the retained species is detrapped, it leaves a vacant trap site behind and a solute excess isotope introduced in the material can be trapped in it hence replacing the initial atom at that trap site. Combined with material annealing, the probability of atom detrapping is higher and the flux of the excess isotopes from surface to bulk is increased and therefore the likelihood of another isotope being trapped in the vacancy increases. Eventually, the detrapped atom diffuses out of the retention region and 
only the excess isotope remains in the vacancies of the material. In laboratory experiments, for safety reasons, D is usually used as a substitute for $\mathrm{T}$.

Even though there have been some experiments and simulations related to isotope exchange, its underlying mechanism is still somewhat unclear.

Conventionally the isotope exchange research focuses on the replacement process of heavy hydrogen isotopes with its lighter isotopes. This effect has been previously studied with plasma exposure experiments [1-5], neutral gases [6] and with ion beams followed by exposure to hydrogen gas [7]. In Ref. [6] it was shown that isotope exchange process can be reversed, i.e. lighter hydrogen isotopes are replaced with heavier isotopes.

In our earlier work we studied isotope exchange rate by implanting $\mathrm{D}$ into polycrystalline $\mathrm{W}$ followed by subsequent annealing in $\mathrm{H}_{2}$ gas at elevated constant temperatures [7]. The results indicated that isotope exchange occurs efficiently at temperatures above $250{ }^{\circ} \mathrm{C}$. The present study focuses on the reversed isotope exchange process and the effect of $\mathrm{H}$ implantation in $\mathrm{W}$ followed by annealing at different constant temperatures under $\mathrm{D}_{2}$ atmosphere. The experimental parameters, such as implantation fluence, annealing temperatures and times, were chosen based on the previous experiments. The present results support well the common assumptions on the underlying physics of the isotope exchange mechanism and highlight the statistical nature of the process.

\section{Experimental}

\subsection{Sample preparation}

The material used was $99.95 \%$ high purity polycrystalline $1 \mathrm{~mm}$ thick W sheet produced by Goodfellow. The samples were polished with diamond suspension with different grain sizes down to $0.25 \mu \mathrm{m}$. After mechanical polishing the samples were cleaned with acetone in an ultrasonic washer. Samples were also flushed with ion-exchanged water and acetone afterwards until there were no particles visible with an optical microscope.

After washing the samples were polished electrochemically up to 4 minutes with $25 \mathrm{~kg} \mathrm{~m}^{-3}$ (2.5 wt.\%) sodium hydroxide $(\mathrm{NaOH})$ solution. Solution was stirred during the polishing process for steady flow over sample surface. Sample to cathode distance was $50 \mathrm{~mm}$ and a voltage of $30 \mathrm{~V}$ was used resulting in $1 \mathrm{~A}$ current. After electropolishing, the samples were washed with ionexchanged water.

Finally, the samples were pre-annealed in vacuum of $10^{-5} \mathrm{~Pa}$ at $1000{ }^{\circ} \mathrm{C}$ for 1.5 hours to remove impurities and to decrease the amount of defects.

\subsection{Ion implantations}

In this paper we compare the present results to our earlier experiments in which implanted $\mathrm{D}$ in $\mathrm{W}$ was replaced by $\mathrm{H}$ from the gaseous phase [7]. In these experiments, D ions were implanted with $60 \mathrm{keV} / \mathrm{D}_{2}$ to a fluence of $5.8 \times 10^{20} \mathrm{D} \mathrm{m}^{-2}$. The implantation created defects in the bulk $\mathrm{W}$, which acted as efficient trapping sites for the implanted $\mathrm{D}$ [8]. In the current experiments, the $\mathrm{H}$ implantation energy was $30 \mathrm{keV} / \mathrm{H}_{2}$ in order to improve the depth resolution for $\mathrm{H}$ in Elastic Recoil Detection Analysis (ERDA) by implanting the ions closer to surface. However, due to the lower mass of $\mathrm{H}$ compared to the mass of $\mathrm{D}$, and due to the lower energy used, the implantations with $\mathrm{H}$ ions produce less vacancies than the previous implantations with D ions. Hence, additional vacancies must be produced to reach the comparable total amount of defects. To produce additional defects in the $\mathrm{H}$-implanted samples the samples were preirradiated with argon (Ar) ions to achieve identical distribution of vacancies compared to $60 \mathrm{keV} / \mathrm{D}_{2}$ implantations. The distributions of the implantation-induced vacancies are shown in Figure 1 as obtained with SRIM simulations using full damage cascades option and with W displacement energy of $90 \mathrm{eV}$. The vacancy types are not exactly identical due to the mass difference of $\mathrm{Ar}$ and D ions: we can expect more vacancy clusters being created with $\mathrm{Ar}$ irradiation [9].

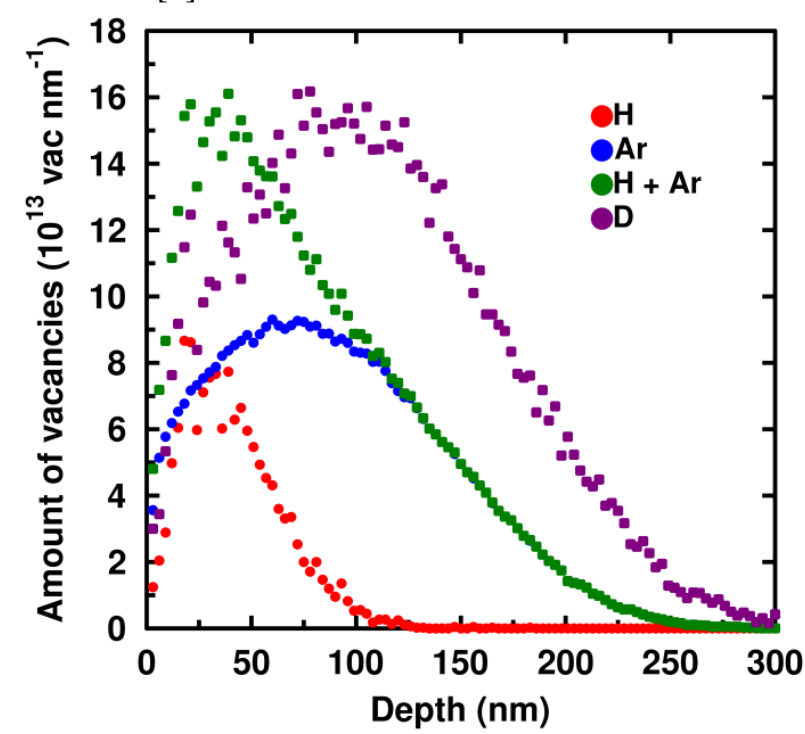

Figure 1. Vacancy depth distributions resulting from $30 \mathrm{keV} / \mathrm{D}, 15 \mathrm{keV} / \mathrm{H}$, and $400 \mathrm{keV} / \mathrm{Ar}$ implantations used in this work as calculated with SRIM. Also shown is the cumulative effect of $\mathrm{H}$ and Ar co-implantation. The total vacancy distribution induced by $\mathrm{H}$ and $\mathrm{Ar}$ is close to the vacancy distribution induced by a $\mathrm{D}$ beam used in previous experiments of Ref. [7]. 
Implantations were done using a $500 \mathrm{kV}$ implanter at University of Helsinki. Two sets of samples were produced: one with and one without $\mathrm{Ar}^{+}$pre-irradiation. Otherwise the samples received the same treatment. Ar irradiations were done with an $\mathrm{Ar}^{+}$beam of $400 \mathrm{keV}$ with a flux of $2.1 \times 10^{15} \mathrm{Ar} /\left(\mathrm{m}^{2} \mathrm{~s}\right)$ to the fluence of $1.0 \times 10^{18} \mathrm{Ar} \mathrm{m}^{-2}$.

$\mathrm{H}$ was implanted into the samples with a flux of $6.2 \times 10^{16} \mathrm{H} /\left(\mathrm{m}^{2} \mathrm{~s}\right)$ to the fluence of $1.0 \times 10^{21} \mathrm{H} \mathrm{m}^{-2}$. The beam was raster scanned over the samples to assure homogeneous distributions. Particle flux was sufficiently low to avoid sample heating. The implantations were done at room temperature.

\subsection{Sample annealing}

The implanted samples were annealed for 4 hours in a quartz tube furnace at different constant temperatures between $200{ }^{\circ} \mathrm{C}$ and $350{ }^{\circ} \mathrm{C}$. The samples were placed next to a K-type thermocouple for temperature monitoring. The samples were annealed in $10^{-5} \mathrm{~Pa}$ vacuum or in $10^{5} \mathrm{~Pa}_{2}$ atmosphere. In the $D_{2}$ annealings the $D_{2}$ gas was introduced as a constant flow to flush the quartz tube. One sample at a time was annealed and a different sample was used for every temperature.

\subsection{Elastic recoil detection analysis}

ERDA was performed with a $25 \mathrm{MeV}{ }^{35} \mathrm{Cl}$ beam at the $5 \mathrm{MV}$ tandem accelerator of University of Helsinki. $\mathrm{Cl}^{5+}$ ions were chosen to maximize the depth resolution and to separate the recoil energies of $\mathrm{H}$ and $\mathrm{D}$. ERDA geometry was horizontal and the scattering angle of $42^{\circ}$ with incident angle of $22^{\circ}$ and with exit angle of $20^{\circ}$ was used. A $4 \mu \mathrm{m}$ Havar foil was used as a stopper foil to exclude the scattered $\mathrm{Cl}$ beam as well as heavy impurities such as carbon and oxygen originating from sample surface. The detector is reported to have a nominal energy resolution of $15 \mathrm{keV}$. The detector was placed $53 \mathrm{~mm}$ from the sample and a collimator with aperture of $2 \mathrm{~mm}$ in width and $7 \mathrm{~mm}$ in height with a solid angle of $5.0 \mathrm{msr}$ was used to improve energy resolution. With the setup $\mathrm{H}$ and D can be separated and analyzed up to $300 \mathrm{~nm}$ in depth. Data was collected in list mode to observe desorption and any possible changes in the depth distribution during the measurement. Error due to statistical uncertainty in the measurements was less than $1 \%$ and their error bars are within the symbol sizes in figures 2 and 3 .

\section{Results}

\subsection{Hydrogen implantation without Ar pre-irradiation}

The ERDA results for the H-only implanted samples show very little evidence of isotope exchange as shown in Figure 2. This can be attributed to the fact that the $30 \mathrm{keV} / \mathrm{H}_{2}$ implantation does not have sufficiently energy to create

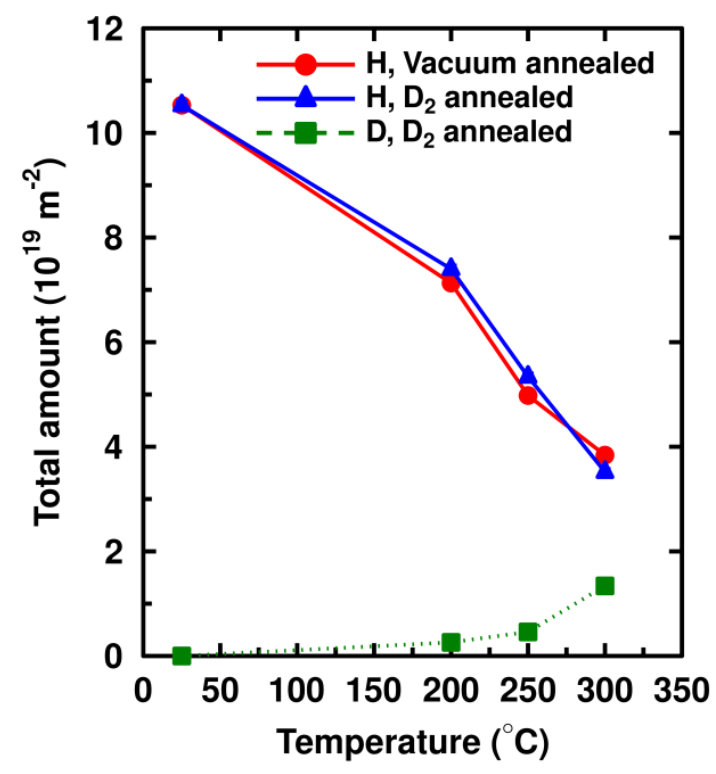

Figure 2. Amount of $\mathrm{H}$ and $\mathrm{D}$ after annealing at constant temperatures up to $300{ }^{\circ} \mathrm{C}$ in samples without $\mathrm{Ar}$ preirradiation.

defects deeper in the bulk which could act as trapping sites for the implanted H. Values shown in Figure 2 are based on the ERDA data and have been obtained by integrating the ERDA spectra for $\mathrm{H}$ and $\mathrm{D}$.

In Figure 2, the amount of remained $\mathrm{H}$ decreases at the same rate regardless the sample being annealed in vacuum or in $\mathrm{D}_{2}$ atmosphere. The amount of $\mathrm{D}$ can be seen gradually increasing: the highest amount of $\mathrm{D}$ was only $1.3 \times 10^{19} \mathrm{D} \mathrm{m}^{-2}$ as measured after $300{ }^{\circ} \mathrm{C}$ annealing, which was the highest temperature in these experiments. The fairly low amount of remained $\mathrm{H}$ and D implies that there were not enough trap sites for these isotopes. SRIM calculation provides an estimate that with the given fluence and energy, only $4 \times 10^{20}$ vac $\mathrm{m}^{-2}$ are produced during the $\mathrm{H}^{+}$ implantation. This is nearly an order of magnitude less than in our previous experiment in which about $2.6 \times 10^{21} \mathrm{vac} \mathrm{m}^{-2}$ were produced during the $\mathrm{D}^{+}$implantation [7]. The vacancies produced by $\mathrm{H}$ are also much closer to sample surface, as seen in Figure 1, limiting the ERDA analysis accuracy since implanted $\mathrm{H}$ was difficult to differentiate from the $\mathrm{H}$ surface background.

\subsection{Hydrogen implantation with Ar pre-irradiation}

As discussed in Sect. 2.2, to solve the problem of deficient number of trap sites for $\mathrm{H}$, we pre-irradiated the samples with $\mathrm{Ar}$ ions. This increased the total amount of vacancies up to $1.7 \times 10^{21} \mathrm{vac} \mathrm{m}^{-2}$ according to SRIM simulations (Figure 1). 


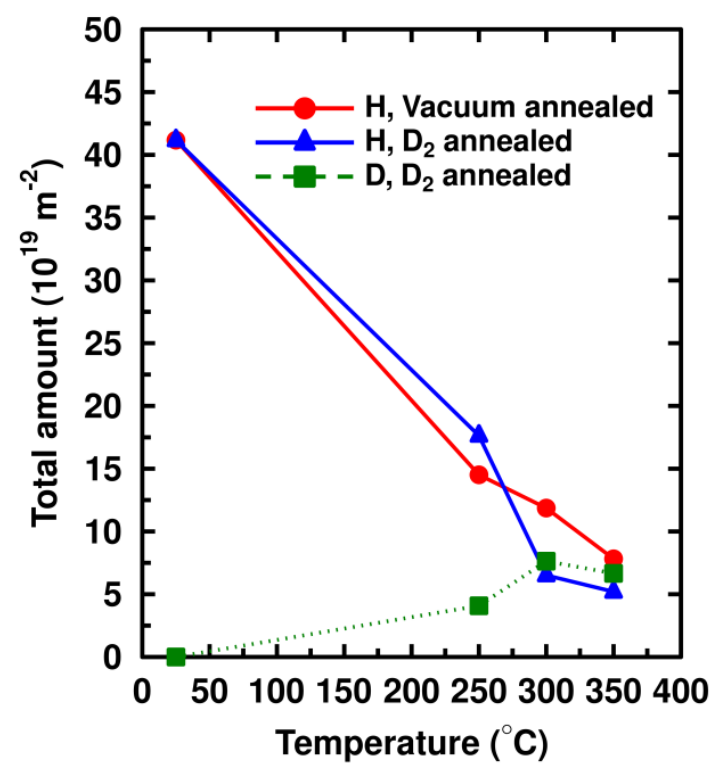

Figure 3. Amount of $\mathrm{H}$ and $\mathrm{D}$ in Ar pre-irradiated samples.

With the Ar-irradiated samples we were able to note significant isotope exchange to take place (Figure 3). By increasing the amount of vacancies with Ar pre-irradiation and thus increasing the amount of trapped $\mathrm{H}$, efficiency of the isotope exchange at various temperatures became clearly visible. At $300{ }^{\circ} \mathrm{C}$, the remained $\mathrm{H}$ in Ar-irradiated samples annealed in vacuum and in $\mathrm{D}_{2}$ atmosphere was measured to be $14 \%$ and only $3 \%$, respectively. The notable difference in the decrease of retained $\mathrm{H}$ at this temperature can be attributed solely to isotope exchange effect taking place when annealed at $\mathrm{D}_{2}$ atmosphere. In general, annealing $\mathrm{W}$ samples in vacuum at $300{ }^{\circ} \mathrm{C}$ and above, the number of hydrogen trapping defects varies as the mono-vacancies become mobile, and the hydrogen detrapping takes place from larger vacancy clusters, or other energetically deep defects. Therefore, annealing at $\mathrm{D}_{2}$ atmosphere using these higher temperatures may show the effect of isotope exchange in deep defects. Figure 3 shows that at $300{ }^{\circ} \mathrm{C}$ and above, in case of vacuum-annealed samples the concentration of retained $\mathrm{H}$ decreases, whereas in case of samples annealed at $\mathrm{D}_{2}$ atmosphere the retained $\mathrm{H}$ decreases more abruptly, and the amount of trapped D increases.

\section{Conclusions}

The present work scrutinizes the underlying mechanism for hydrogen isotope exchange by reversing the conventional process. As a result, it was shown that the isotope exchange takes place not only when heavy hydrogen isotopes are replaced with lighter ones, but also when lighter isotopes are replaced with heavier ones. This is in agreement with observations noted in other experiments $[1,6]$, in which the isotope exchange has been seen to take place more likely when replacing light isotopes with heavy ones [6]. The exchange process is statistical in nature; the amount of the added excess solute isotopes in the bulk near the detrapped initial isotopes plays a crucial role, and eventually majority of the vacancies will be filled by the excess isotopes as the detrapped initial isotopes diffuse out. Temperature is an essential parameter as it affects the detrapping rates as well as the flux from surface to bulk during annealing in gas atmosphere. Annealing at $300{ }^{\circ} \mathrm{C}$ in $\mathrm{D}_{2}$ atmosphere resulted in a very low retained $\mathrm{H}$ concentration. On the other hand annealing in vacuum requires about $100{ }^{\circ} \mathrm{C}$ higher temperatures to achieve identical reduction in $\mathrm{H}$ retention. At $250{ }^{\circ} \mathrm{C}$ the effectiveness of isotope exchange is not as good; at low temperatures the flux from the surface to the bulk is reduced becoming the limiting factor in isotope exchange. This is because the $\mathrm{W}$ surface sites are saturated with $\mathrm{D}$ during the D-atmosphere annealing, and the potential energy barrier for a $\mathrm{D}$ atom from the sample surface to the bulk is assessed to be not more than $2 \mathrm{eV}$ [10]. The flux of D atoms from the surface to bulk follows the Arrhenius equation in which the flux decreases fast as the temperature decreases. The measured temperature dependence of the isotope exchange process highlights the importance of the excess solute isotopes in the process. Through the performed experiments better understanding of the processes behind isotope exchange could be achieved.

\section{Acknowledgements}

This work received funding from Academy of Finland (no. 297866)

\section{References}

[1] Roth J, Schwarz-Selinger T, Alimov V K and Markina E 2013 J. Nucl. Mater. 432 341-7

[2] Alimov V K, Khripunov B I, Spitsyn A V, Hatano Y, Golubeva A V, Gureev V M and Petrov V B 2016 Probl. At. Sci. Technol. Ser. Thermonucl. Fusio 36 61-7

[3] Alimov V K, Tyburska-Püschel B, 'T Hoen M H J, Roth J, Hatano Y, Isobe K, Matsuyama M and Yamanishi T 2011 Phys. Scr. T T145

[4] Barton J L, Wang Y Q, Schwarz-Selinger T, Doerner R P and Tynan G R 2013 J. Nucl. Mater. 438 S1183-6

[5] Takagi I, Nomura S, Minamimoto T, Akiyoshi M, Kobayashi T and Sasaki T 2015 J. Nucl. Mater. 4631125 8

[6] Markelj S, Založnik A, Schwarz-Selinger T, Ogorodnikova O V., Vavpetič P, Pelicon P and Čadež I 2016 J. Nucl. Mater. 469 133-44

[7] Ahlgren T, Jalkanen P, Mizohata K, Tuboltsev V, Räisänen J, Heinola K and Tikkanen P 2019 Nucl. Fusion 5926016

[8] Heinola K, Ahlgren T, Vainonen-Ahlgren E, Likonen J and Keinonen J 2007 Phys. Scr. T128 91-5

[9] Zhu X-L, Zhang Y, Cheng L, Yuan Y, Temmerman G De, Wang B-Y, Cao X-Z and Lu G-H 2016 Nucl. Fusion 56 36010

[10] Heinola K and Ahlgren T 2010 Phys. Rev. B 8173409 